\title{
A scoping review and mapping exercise comparing the content of patient-reported outcome measures (PROMs) across heart disease-specific scales
}

Beatrix Algurén ${ }^{1,2^{*}}$ (D) Michaela Coenen ${ }^{3,4,5}$, Dan Malm², Bengt Fridlund ${ }^{7}$, Jan Mårtensson ${ }^{6}$, Kristofer Årestedt ${ }^{8,9}$ and on behalf of the Collaboration and Exchange in Swedish cardiovascular caring Academic Research (CESAR) group

\begin{abstract}
Background: Over the past decade, the importance of person-centered care has led to increased interest in patientreported outcome measures (PROMs). In cardiovascular care, selecting an appropriate PROM for clinical use or research is challenging because multimorbidity is often common in patients. The aim was therefore to provide an overview of heartdisease specific PROMs and to compare the content of those outcomes using a bio-psycho-social framework of health.

Methods: A scoping review of heart disease-specific PROMs, including arrhythmia/atrial fibrillation, congenital heart disease, heart failure, ischemic heart disease, and valve diseases was conducted in PubMed (January 2018). All items contained in the disease-specific PROMs were mapped to WHO's International Classification of Functioning, Disability and Health (ICF) according to standardized linking rules.

Results: A total of 34 PROMs (heart diseases in general $n=5$; cardiac arrhythmia $n=6$; heart failure $n=14$; ischemic heart disease $n=9$ ) and 147 ICF categories were identified. ICF categories covered Body functions ( $n=61)$, Activities \& Participation ( $n=69)$, and Environmental factors $(n=17)$. Most items were about experienced problems of Body functions and less often about patients' daily activities, and most PROMs were specifically developed for heart failure and no PROM were identified for valve disease or congenital heart disease.
\end{abstract}

Conclusions: Our results motivate and provide information to develop comprehensive PROMs that consider activity and participation by patients with various types of heart disease.

Keywords: International Classification of Functioning, Disability and Health, Heart disease, Healthcare quality, Patient outcome assessment, Patient-reported outcome measures, Person-centered, Review

\footnotetext{
*Correspondence: Beatrix.alguren@gu.se

The responsibility for this publication lies with the authors.

'Department of Food and Nutrition, and Sport Science, Faculty of Education,

University of Gothenburg, PO Box 300, 40530 Gothenburg, Sweden

${ }^{2}$ The Jönköping Academy for Improvement of Health and Welfare, School of

Health Sciences, Jönköping University, Jönköping, Sweden

Full list of author information is available at the end of the article
} 


\section{Background}

Heart disease is a common and increasing health problem worldwide [1]. Independent of diagnosis and etiology, heart diseases usually have a significant negative impact on people's quality of life (QoL) and well-being with high symptom burden, emotional reactions, reduced physical capacity, and social isolation [2-6]. Over the past decade, the importance of person-centered care, which includes patients' experiences of diseases and their impact on their daily lives, has been recognized [710]. Despite the fact that different definitions of "centeredness" exist within the literature (e.g. "patient", "client", or "customer"), they have three overarching common themes: a) an understanding of the person and their lived experience of health conditions and disability by taking a holistic view of health with recognition of psycho-social factors beyond just bodily functions and anatomical structures, b) patient empowerment in decision making, and c) the creation of relationships in care and treatment and the promotion of trust formed by continuity and coordination [11]. Understanding patients' experiences of health conditions and disability and those issues that are important but less obvious to healthcare professionals can be assessed through patient-reported outcome measures (PROMs). PROMs have been defined as "... any report of the status of a patient's health condition that comes directly from the patient (i.e., without the interpretation of the patient's responses by a physician or anyone else)" [12] (p1). Thus, PROMs can be seen as an umbrella term for selfrating instruments that measure constructs such as health, health-related states, health-related QoL, wellbeing, and symptoms among other things [13], and they have been shown to be an important aspect of healthcare quality and value-based healthcare [14-17].

Selecting an appropriate PROM for clinical use or research is challenging not least because multimorbidity is common in patients with cardiovascular disease [18]. For example, a common sequela of multimorbidity is the co-existence of heart failure, atrial fibrillation, and hypertension, and these are often seen in combination with depression and chronic kidney disease [19]. The advantage of disease-specific versus generic PROMs are that disease-specific PROMs are more specific and sensitive to capture the distinctive problems that patients with a specific health condition experience. In case of multimorbidity, one disease-specific PROM might not portray the broad range of experienced problems and disease-specific PROMs for each morbidity should be used instead. However, this will increase the risk for content overlapping and thereby increase respondent's burden without adding new information. In order to facilitate the selection of proper disease-specific PROMs or even only a generic set of important items for patients with various heart diseases, there is a need to analyze and compare existing instruments in order to get a better understanding of their content (i.e. items). For describing and comparing health information from outcome measures across diagnoses, the International Classification of Functioning, Disability and Health (ICF) from the World Health Organization (WHO) has been identified as a useful tool [20]. The ICF provides a common framework and a neutral language to describe health and health-related states from a bio-psycho-social perspective and comprises Body functions, Body structures, Activities \& Participation, Environmental factors, and Personal factors [21]. The overall aim of this literature review was to provide an overview of heart-disease specific PROMs and to compare the content of those outcome measures using the ICF as a framework. This knowledge is of importance for clinicians and researchers in order to select appropriate PROMs for different kinds of care, treatments, clinical settings, and research purposes. It will give a better understanding of the common aspects of PROMs in the field of heart diseases from a bio-psycho-social perspective as well as identify what aspects are missing and need further development.

\section{Methods \\ Design}

A scoping review was conducted to get an overview of all existing disease-specific PROMs for patients with heart diseases, including heart diseases in general, ischemic heart disease, heart failure, arrhythmia, valve disease, and/or grown-up congenital heart disease [22]. The items of the identified PROMs were compared using the ICF as a framework.

\section{Scoping review of disease-specific PROMs}

The systematic literature search was carried out in PubMed. A series of pilot searches were conducted during 2017 to identify relevant search terms. The pilot searches were discussed with an university librarian with special competence in medical science and literature searches. Based on this the following search terms and truncations were identified; questionnaire*, valid*, scale*, index*, develop*, heart disease*, ischemic heart disease*, angina*, myoc", heart failure, arrhythmia, atrial, valve heart disease", and congenital heart disease*. Together with the librarian, we also constructed multiple search combinations of these terms for each cardiac diagnose, with restrictions to the title (Additional file 1). The final search was conducted in January 2018 and was limited to English articles, while no limitations were used for publication type or year. Abstracts identified in the search were screened and selected based on the following two inclusion criteria: (1) PROMs 
developed or modified specifically for patients with heart disease in general or ischemic heart disease, heart failure, arrhythmia, valve diseases, and congenital heart disease and (2) some kind of validation process. Exclusion criteria were the following: PROMs developed for children and adolescent (aged under 18 years), PROMs measuring single symptoms or domains (e.g. fatigue, knowledge, risk behaviors, or locus of control), and patient-reported experience measures (e.g. measurements of treatment satisfaction). In total, 32 PROMs were identified, including short versions of two questionnaires. Additionally, an expert consultation was conducted. In doing so, four PROMs were identified by the expert group - the Collaboration and Exchange in Swedish cardiovascular caring Academic Research (CESAR) network (www.cesar-network.com). In total, 34 PROMs were included in the present mapping exercise, excluding the short versions of two instruments (Fig. 1).

\section{Content comparison of disease-specific PROMs}

All items contained in the identified 34 disease-specific PROMs were mapped to the ICF according to standardized and established linking rules [23-25] first by identifying linking units in the items and second by mapping these linking units to the most specific ICF category (1st to 4th level of classification). A linking unit is a piece of information with the same meaning and often correspond to one item of a questionnaire. For example, one question in the Patient Perspective of Arrythmia Questionnaire (PPAQ) is 'In the past 4 weeks, how often on average did your fast heart rhythm occur?', where 'heart rhythm' is the specific linking unit and b4101 (heart rhythm) the corresponding ICF category. Another example from the same questionnaire is the question 'During the past 4 weeks, how many days did you miss work or school due to your fast heart rhythm?', with one linking unit 'missing work' linked to d850 (Remunerative

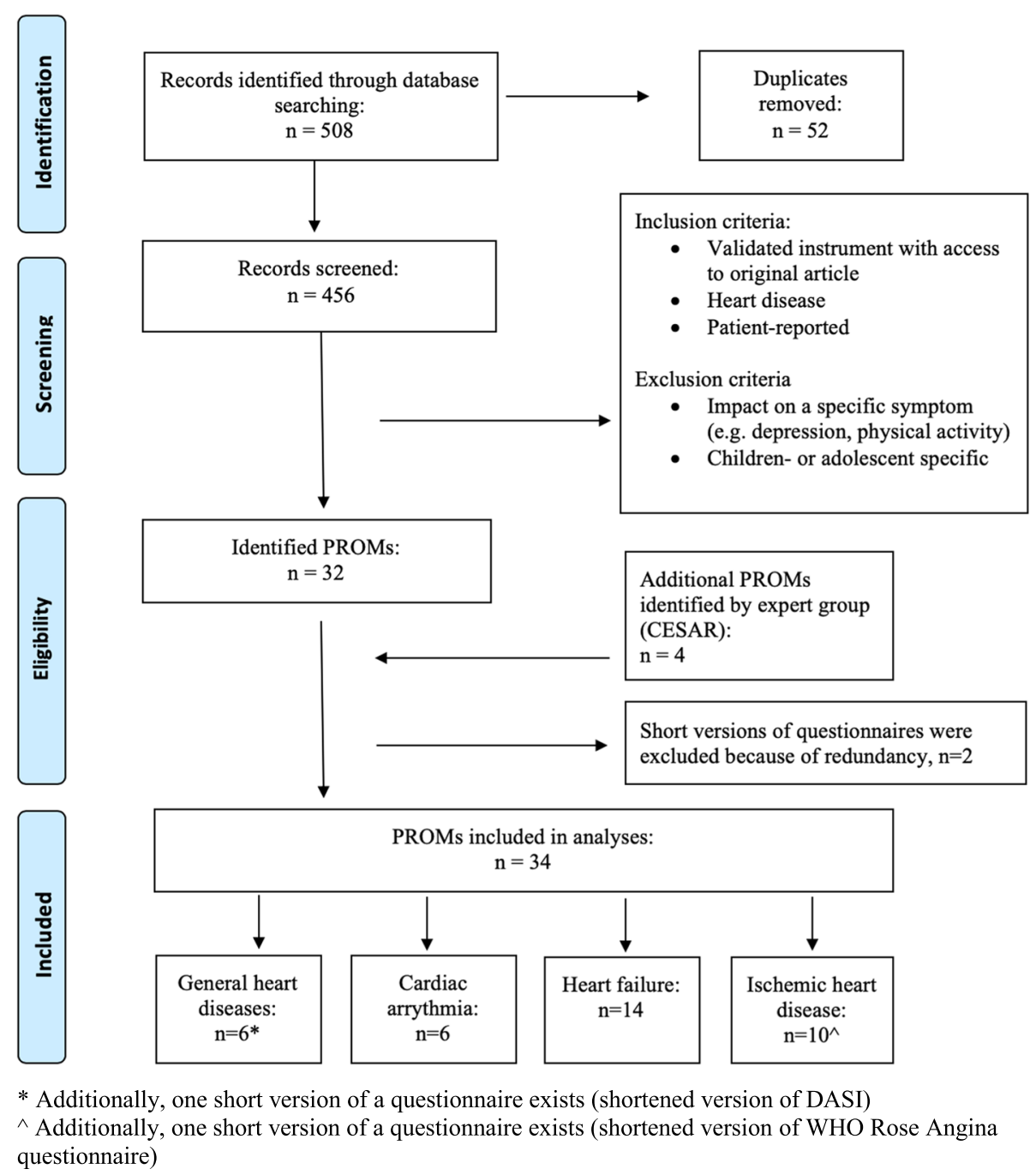

Fig. 1 Flow diagram of the literature search in PubMed, conducted in January 2018 
employment) and the second is 'missing school' linked to d820 (School education). If a linking unit was not addressed by the ICF, the option "not covered" was chosen (e.g. "Having a chance for a happy future" or "Family's health"). Concepts referring to Personal factors were mapped to this component of the ICF (pf - "Satisfaction with oneself in general"). However, because Personal factors are not further classified, no specific ICF codes were assigned and thus were not included in the following tables and figures.

Identification of linking units and mapping ("linking") to the ICF was performed independently by two researchers experienced in the application of the ICF linking rules (BA, physical therapist; $\mathrm{MC}$, psychologist). Consensus between the two researchers was achieved to decide which ICF category should be linked to each linking unit. In case of disagreement, the arguments were discussed until consensus on the final category was reached. Descriptive statistics were performed to provide absolute and relative frequencies of linked ICF categories.

\section{Results}

\section{Disease-specific PROMs for heart diseases}

Table 1 gives an overview of the identified instruments. In total, 34 PROMs were found by the scoping review and expert consultation, but the Duke Activity Status Index (DASI) and WHO Rose Angina questionnaire also exist as short versions and these versions were not explicitly analyzed in the present study. Of all identified PROMs, 5 are designed for use in patients with heart diseases in general, 6 for patients with cardiac arrhythmia, 14 for patients with heart failure, and 9 for patients with ischemic heart disease. No PROM was found for valve diseases or for congenital heart disease.

\section{Content of PROMs from a bio-psycho-social perspective}

In total, the items of the PROMs could be mapped to 147 ICF categories covering 61 Body functions, 69 Activities \& Participation, and 17 Environmental factors (see Additional files 2, 3 and 4). The PROMs that included most aspects of functioning were the Patient Perception of Arrhythmia Questionnaire (PPAQ) (27 ICF categories), the Memorial Symptom Assessment Scale-Heart Failure (MSAS-HF) (26 ICF categories), and the Summary Index for the Assessment of Quality of Life in Angina Pectoris (25 ICF categories) (Table 2). These included items that covered Body functions such as "Temperament and personality functions" (b126) but as well Activities E Participation such as "Recreation and leisure" (d920). Overall, Body functions were most frequently asked about and were included in all 34 PROMs, while 28 PROMS addressed Activities \& Participation, 16 addressed Environmental factors, and 12 addressed Personal factors.

Table 2 and Fig. 2 give an overview of the content of the PROMs.

\section{Body functions}

All PROMs besides the DASI, which addressed only Activities $\mathcal{E}$ Participation, covered at least one body function. In total, 61 ICF categories were identified. The most frequently linked category was "Emotional functions" (b152), which was addressed in 29 (85\%) PROMs, and this was followed by "Energy level" (b1300) $(n=26,77 \%)$, and "Sensations associated with cardiovascular and respiratory functions" (b460) ( $n=23,68 \%)$ (Additional file 2 and Fig. 2). "Exercise tolerance functions" (b455), "Sensation of pain" (b280), and "Temperament and personality functions" (b126) were included in half of the PROMs.

\section{Activities \& participation}

Thirty out of the 34 PROMs covered aspects referring to Activities \& Participation. The six PROMs that did not covered any aspects of Activities \& Participation at all were Atrial Fibrillation (AF6), the Quality of Life Symptom based for Atrial Fibrillation Questionnaire (QLAF), the Cardiac Health Profile of Congestive Heart Failure (CHPchf), the Heart Failure Somatic Awareness Scale (HFSAS), the Symptom Status Questionnaire - Heart Failure (SSQ-HF), and the Traditional Chinese Medicine inquiry (TCM inquiry). In total, 69 categories were identified, and the most frequently mapped categories were "Recreation and leisure" (d920), which includes sports and running and was addressed in 19 instruments (56\%), "Moving around" (d455), which includes climbing stairs and was addressed in 15 PROMs (44\%), and "Doing housework" (d640), which was addressed in 12 PROMs (35\%) (Additional file 3 and Fig. 2).

\section{Environmental factors and personal factors}

Almost half of the PROMs $(n=16)$ addressed Environmental factors. In total, 15 categories were identified, with the most frequently linked categories being "Drugs" (e1101), which was addressed in 9 (27\%) PROMs and "Immediate family" and "Health services" (e310 and e5500), which were both addressed by 4 (12\%) PROMs (Additional file 4 and Fig. 2). Twelve of the 34 PROMs included one or two questions addressing Personal factors (the most common were, for example, Being bothered by having problems, Having difficulties relaxing, and Feeling like a burden to the family, with the exception of the Quality of Life Index (QLI) that included about 15 questions on satisfaction and importance of, for example, Peace of mind, Faith in God, and Achievement of personal goals. 
Table 1 Overview of the heart-disease specific PROMs identified by the systematic literature search $(N=34)$

\begin{tabular}{|c|c|c|}
\hline Name of PROMs & Abbreviation & Reference \\
\hline \multicolumn{3}{|l|}{ Heart diseases in general $(n=5)$} \\
\hline $\begin{array}{l}\text { Duke Activity Status Index } \\
\text { (Duke Activity Status Index - short) }\end{array}$ & $\begin{array}{l}\text { DASI } \\
\text { (DASI - short) }\end{array}$ & $\begin{array}{l}\text { Hlatky MA et al., } 1989 \text { [26] } \\
\text { (Alonso J et al., } 1997 \text { [27]) }\end{array}$ \\
\hline HeartQoL Questionnaire & HeartQoL & Oldridge $\mathrm{N}$ et al., 2013 [28] \\
\hline Multidimensional Index of Life Quality ${ }^{a}$ & MILQ & Avis NE et al., 1996 [29] \\
\hline Quality of Life Index - Cardiac version - IV & QLI cardiac version & Ferrans C \& Powers M, 1985 [30] \\
\hline Quality of Life Instruments for Chronic Diseases - coronary heart disease & QLICD-CHD & Wan et al., 2014 [31] \\
\hline \multicolumn{3}{|l|}{ Cardiac arrythmia $(n=6)$} \\
\hline AF-QoL Questionnaire & AF-QoL-40 & Badia X et al., 2007 [32] \\
\hline Arrhythmia-specific Questionnaire in Tachycardia and Arrhythmia & ASTA & $\begin{array}{l}\text { Walfridsson U et al., } 2012 \text { [33] } \\
\text { Walfridsson U et al., } 2015 \text { [34] }\end{array}$ \\
\hline Atrial Fibrillation & AF6 & Härdén M et al., 2009 [35] \\
\hline Atrial Fibrillation Effect on Quality-of-Life Questionnaire & AFEQT & Spertus J et al., 2011 [36] \\
\hline Patient Perception of Arrhythmia Questionnaire & PPAQ & Wood KA et al., 2009 [37] \\
\hline Quality of Life Symptom based for Atrial Fibrillation Questionnaire & QLAF & Braganca EO et al., 2010 [38] \\
\hline \multicolumn{3}{|l|}{ Heart failure $(n=14)$} \\
\hline Cardiac Health Profile of Congestive Heart Failure & CHPchf & Mannheimer B et al., 2007 [39] \\
\hline Care-Related Quality of Life survey for Chronic Heart Failure & CaReQoL CHF & Van Kessel P et al., 2017 [40] \\
\hline Chronic Heart Failure Questionnaire & $\mathrm{CHQ}$ & Guyatt GH et al., 1989 [41] \\
\hline Congenital Heart Disease-TNO/AZL Adult Quality of Life ${ }^{a}$ & CHD-TAAQOL & Kamphuis M et al., 2004 [42] \\
\hline Fragebogen zur Erfassung körperlichen Wohlbefindens & FEW16 & Kolip P et al., 1999 [43] \\
\hline Heart Valve Disease Impact on daily life & IDCV & Padilha et al., 2007 [44] \\
\hline Heart Failure Somatic Awareness Scale & HFSAS & Jurgens CY et al., 2006 [45] \\
\hline Kansas City Cardiomyopathy Questionnaire & $\mathrm{KCCQ}$ & Green CP et al., 2000 [46] \\
\hline Left Ventricular Dysfunction Questionnaire & LVD-36 & O'Leary CJ \&Jones PW, 2000 [47] \\
\hline Memorial Symptom Assessment Scale-Heart Failure ${ }^{a}$ & MSAS-HF & Zambroski CH et al., 2005 [48] \\
\hline Minnesota Living with Heart Failure Questionnaire & MLHF & Rector TS et al., 1987 [49] \\
\hline Quality of Life Questionnaire in Severe Heart Failure & QLQ-SHF & Wiklund I et al., 1987 [50] \\
\hline Symptom Status Questionnaire - Heart Failure & SSQ-HF & Heo S et al., 2014 [51] \\
\hline Traditional Chinese Medicine inquiry & TCM inquiry & Fu TC et al., 2016 [52] \\
\hline \multicolumn{3}{|l|}{ Ischemic heart disease $(n=9)$} \\
\hline Angina-related Limitations at Work Questionnaire & ALWQ & Lerner DJ et al., 1998 [53] \\
\hline Angina Pectoris Quality of Life Questionnaire & APQLQ & Marquis P et al., 1995 [54] \\
\hline Cardiovascular Limitations and Symptoms Profile & CLASP & Lewin RJ et al., 2002 [55] \\
\hline Myocardial Infarction Dimensional Assessment Scale & MIDAS & Thompson DR et al., 2002 [56] \\
\hline Quality of Life Index & QLI & Rukholm E, et al., 1994 [57] \\
\hline Quality of Life Questionnaire & QLMI-2 & Valenti L, et al., 1996 [58] \\
\hline Seattle Angina Questionnaire & SAQ & Spertus JA et al., 1995 [36] \\
\hline Summary Index for the Assessment of Quality of Life in Angina Pectoris ${ }^{a}$ & & Wilson A et al., 1991 [59] \\
\hline $\begin{array}{l}\text { WHO Rose Angina Questionnaire } \\
\text { (Shortened WHO Rose Angina Questionnaire) }\end{array}$ & & $\begin{array}{l}\text { Rose GA, } 1962 \text { [60] } \\
\text { (Lawlor DA et al., } 2003 \text { [61]) }\end{array}$ \\
\hline
\end{tabular}


Table 2 Overview of the number of different aspects measured by each PROM $(n=34)$ linked to ICF chapters

\begin{tabular}{|c|c|c|c|c|c|c|c|c|c|c|c|c|c|c|c|c|c|c|c|c|c|c|c|c|c|c|c|c|c|c|c|c|c|c|}
\hline \multicolumn{2}{|c|}{ ICF categories } & \multicolumn{5}{|c|}{$\begin{array}{c}\text { Heart diseases in } \\
\text { general }\end{array}$} & \multicolumn{6}{|c|}{ Cardiac arrythmia } & \multicolumn{12}{|c|}{ Heart failure } & \multicolumn{9}{|c|}{ Ischemic heart disease } & \\
\hline $\begin{array}{l}\text { ICF } \\
\text { code }\end{array}$ & ICF title & $\overline{\mathrm{g}}$ & & & 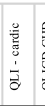 & 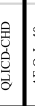 & $\begin{array}{l}8 \\
\\
\end{array}$ & & & & & & 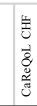 & g: & & $\stackrel{\circ}{\mathbf{E}^{2}}$ & 离 & 暗 & & 恶 & 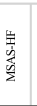 & 崖 & & 密 & 童 & 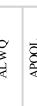 & & $\frac{a_{0}^{\circ}}{2}$ & & 产 & & & & \\
\hline \multicolumn{34}{|c|}{ Body functions } & \\
\hline b1 & Mental Functions & 0 & 3 & 5 & 2 & 3 & 8 & 6 & 2 & 35 & 50 & 3 & & 2 & 1 & 3 & 4 & 1 & 2 & 5 & 6 & 5 & 6 & & & & & 36 & & 6 & 1 & 14 & & 37 \\
\hline b2 & Sensory functions and pain & 0 & 0 & 1 & 1 & 4 & 0 & 2 & 0 & 1 & $5 \quad 2$ & o & 0 & 0 & 1 & 0 & 1 & 0 & 0 & 0 & 4 & 0 & 1 & & 4 & & 1 & $0 \quad 3$ & 1 & 3 & 1 & 2 & ${ }^{2} 4$ & 43 \\
\hline 64 & Functions of cardio./haematol./immunol./respiratory syst. & 0 & 1 & 0 & 1 & 1 & 3 & 4 & 3 & 3 & $5 \quad 1$ & & 0 & 0 & 3 & 0 & 1 & 4 & 3 & 3 & 4 & 3 & 2 & & 3 & & 23 & 31 & 0 & 3 & 1 & 2 & 1 & 70 \\
\hline b5 & Functions of the digestive, metabolic and endocrine syst. & 0 & 0 & 0 & 0 & 0 & 0 & 0 & 0 & 0 & 20 & (c) & 0 & 0 & 0 & 0 & 0 & 2 & 0 & 2 & 7 & 0 & 0 & 0 & 0 & 0 & 0 & $0 \quad 1$ & 1 & 0 & 0 & 0 & 0 & 15 \\
\hline b6 & Genitourinary and reproductive functions & 0 & 0 & 0 & 0 & & 1 & 1 & 0 & 0 & 100 & ( & $\begin{array}{ll}0 & 0\end{array}$ & 0 & 1 & 0 & 0 & 0 & 0 & 0 & 2 & 0 & 0 & & 0 & 0 & $0 \quad 1$ & 10 & 1 & 0 & 0 & 0 & 0 & $\theta$ \\
\hline b7 & Neuromusculoskeletal and movement-related fcts. & 0 & 0 & 0 & 0 & 0 & 0 & 0 & 0 & 0 & 00 & (c) & 0 & 0 & 0 & 0 & 0 & 0 & 0 & 1 & 0 & 0 & 0 & 0 & 1 & 0 & 00 & $\begin{array}{ll}0 & 0\end{array}$ & 0 & 0 & 0 & 0 & & \\
\hline b8 & Functions of the skin and related structures & 0 & 0 & 0 & 0 & 0 & 0 & 1 & 0 & 0 & 10 & ( & 0 & 0 & 0 & 0 & 0 & 0 & 0 & 0 & 2 & 0 & 0 & 0 & 0 & 0 & 00 & 00 & 0 & 0 & 0 & 0 & 0 & 4 \\
\hline \multicolumn{35}{|c|}{ Activities and Participation } \\
\hline$d 1$ & Learning and applying knowledge & 0 & 0 & 1 & 0 & 0 & 0 & 0 & 0 & 0 & 00 & a & 0 & 0 & 0 & 0 & 0 & 0 & 0 & 0 & 1 & 0 & 0 & 0 & & & 00 & $0 \quad 0$ & 0 & 0 & 0 & 1 & 0 & \\
\hline$d 2$ & General tasks and demands & 0 & 0 & 1 & 0 & 0 & 1 & 1 & 0 & 00 & 0 & 0 & 1 & 0 & 0 & 1 & 0 & 0 & 0 & 0 & 0 & 0 & 0 & & 0 & & & 0 & 0 & 0 & 0 & & 0 & \\
\hline d3 & Communication & 0 & 0 & 0 & 0 & 0 & 0 & 0 & 0 & 0 & 00 & ( & 0 & 1 & 0 & 0 & 0 & 0 & 0 & 0 & 0 & 0 & 0 & & 0 & & 00 & 00 & 0 & 0 & 0 & & 0 & \\
\hline$d 4$ & Mobility & 6 & 4 & 1 & 0 & 0 & 5 & 0 & 0 & 3 & 20 & & 2 & 8 & 4 & 0 & 0 & 0 & 1 & 2 & 0 & 2 & 3 & & 0 & 2 & 25 & 50 & 0 & 0 & 5 & & 7 & 56 \\
\hline$d 5$ & Self-care & 4 & 0 & 0 & 2 & 1 & 0 & 0 & 0 & 0 & $\begin{array}{ll}0 & 0\end{array}$ & 0 & 0 & 3 & 1 & 0 & 1 & 0 & 2 & 2 & 0 & 0 & 0 & & 0 & 0 & $\begin{array}{ll}0 & 0\end{array}$ & $0 \quad 1$ & 1 & 0 & 2 & & 1 & 21 \\
\hline$d 6$ & Domestic life & 2 & 2 & 0 & 1 & 0 & 0 & 0 & 0 & 0 & 10 & 0 & 1 & 6 & 0 & 0 & 0 & 0 & 2 & 2 & 0 & 2 & 1 & & 0 & 0 & 22 & 21 & 0 & 0 & 5 & & 0 & 32 \\
\hline$d 7$ & Interpersonal interactions and relationships & 1 & 0 & 0 & 2 & 0 & 2 & 0 & 0 & 0 & 20 & 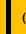 & 02 & 0 & 3 & 0 & 1 & 0 & 1 & 1 & 0 & 2 & 0 & 0 & 0 & 0 & 0 & 00 & 1 & 0 & 0 & & 0 & 18 \\
\hline$d 8$ & Major life areas & 0 & 0 & 2 & 4 & 0 & 0 & 2 & 0 & 0 & 20 & ( & 0 & 0 & 2 & 0 & 1 & 0 & 1 & 0 & 0 & 1 & 0 & 0 & 0 & 1 & 0 & 00 & 0 & 0 & 0 & 1 & 0 & 17 \\
\hline$d 9$ & Recreation and leisure & 1 & 1 & 0 & 1 & 0 & 1 & 1 & 0 & 3 & 10 & $\mathrm{c}$ & 0 & 2 & 1 & 0 & 0 & 0 & 2 & 3 & 0 & 4 & 0 & 0 & 0 & 0 & 2 & 12 & 1 & 2 & 1 & & 0 & 32 \\
\hline \multicolumn{35}{|c|}{ Environmental factors } \\
\hline el & Products and technology & 0 & 0 & 1 & 1 & 0 & 1 & 1 & 0 & 1 & 01 & ( & 0 & 0 & 1 & 0 & 0 & 0 & 0 & 1 & 0 & 2 & 0 & 0 & 0 & 0 & 00 & 0 & 0 & 0 & 1 & 0 & 0 & 12 \\
\hline e2 & Natural environment and human-made changes to envir. & 0 & 0 & 0 & 0 & 0 & 1 & 0 & 0 & 0 & 00 & 2 & 20 & 0 & 0 & 0 & 0 & 0 & 0 & 1 & 0 & 0 & 0 & & 0 & 0 & 0 & 01 & 0 & 0 & 0 & 0 & & \\
\hline$e 3$ & Support and relationships & 0 & 0 & 1 & 4 & 0 & 1 & 0 & 0 & 0 & 0 & 0 & 1 & 0 & 0 & 0 & 0 & 0 & 0 & 1 & 0 & 0 & 0 & 0 & 0 & 0 & $0 \quad 0$ & $0 \quad 2$ & 1 & 1 & 1 & 0 & 0 & \\
\hline$e 4$ & Attitudes & 0 & 0 & 0 & 0 & 0 & 0 & 0 & 0 & 0 & 0 & 0 & 0 & 0 & 0 & 0 & 0 & 0 & 0 & 0 & 0 & 0 & 0 & 0 & 0 & 0 & $0 \quad 0$ & 0 & 0 & 1 & 0 & & 0 & 1 \\
\hline \multirow[t]{2}{*}{ es } & Services, systems and policies & 0 & 0 & 1 & 1 & 0 & 0 & 0 & 0 & 1 & 01 & & 1 & & 1 & 0 & 0 & 0 & 0 & 0 & 0 & 0 & 0 & 0 & 0 & 0 & 0 & $0 \quad 0$ & 0 & 0 & 1 & 0 & 0 & \\
\hline & n (tot & & & & & & & & & & & & & & & & & & & & & & & & & & & & & & & & & \\
\hline
\end{tabular}

The numbers represent how many questions on each questionnaire addressed the respective ICF chapter. Darker colors present higher number of questions

\section{Aspects not covered in the ICF or aspects that are not defined}

Single PROMs asked individual questions about aspects that are not covered by the ICF or are not defined, including "Deteriorated life situation" (asked in the Arrhythmia-specific Questionnaire in Tachycardia and Arrhythmia (ASTA)) and "Staying at the hospital" (asked in the Minnesota Living with Heart Failure Questionnaire (MLHF)), or are time-related aspects like "Duration of treatment' (asked in the QLAF), "Cutting down on the things that usually need to be done" (asked in the PPAQ), and "Limitations in daily life/day-to-day activities" (asked in 8 PROMs).

\section{Discussion}

With this work we provide an overview of existing heart disease-specific PROMs and compare the content of these PROMs using the ICF as a framework. Thirty-four diseasespecific PROMs for use in heart diseases were identified (additionally, there were short forms of two of the included PROMs), and a total of 147 different ICF categories in the WHO's bio-psycho-social framework were identified in the PROMs. Most items concerned experienced problems of Body functions, but less often asked about the impact of these symptoms on patients' daily activities. Moreover, this study showed that most PROMs were specifically developed for heart failure, and no PROMs were identified for valve diseases or for congenital heart disease.

With the increasing interest in using PROMs, there is a need for healthcare professionals and/or researchers to choose the most appropriate PROM. It is thus of importance to carefully consider the content of the PROM before its use in order to ensure that a given PROM covers important aspects of interest for care management of individual patients and for quality improvement [14, 15, 62, 63]. The present review and content comparison revealed that, for example, for heart disease in general the most comprehensive PROM was the QLI-cardiac version that focuses on problems in major life areas (e.g. employment and education) as well as support and relationships with family and friends. If focus should be on activities of daily living, e.g. washing, dressing, walking, and climbing stairs, the DASI might be more appropriate to choose, whereas the Multidimensional Index of Life Quality (MILQ) might be more appropriate if the focus is on mental functions like energy level, motivation, and mood.

In cardiac arrhythmia, the most comprehensive diseasespecific instrument was the PPAQ with a main focus on problems within mental, sensory, and cardiovascular functions but also with a broader view on problems regarding 


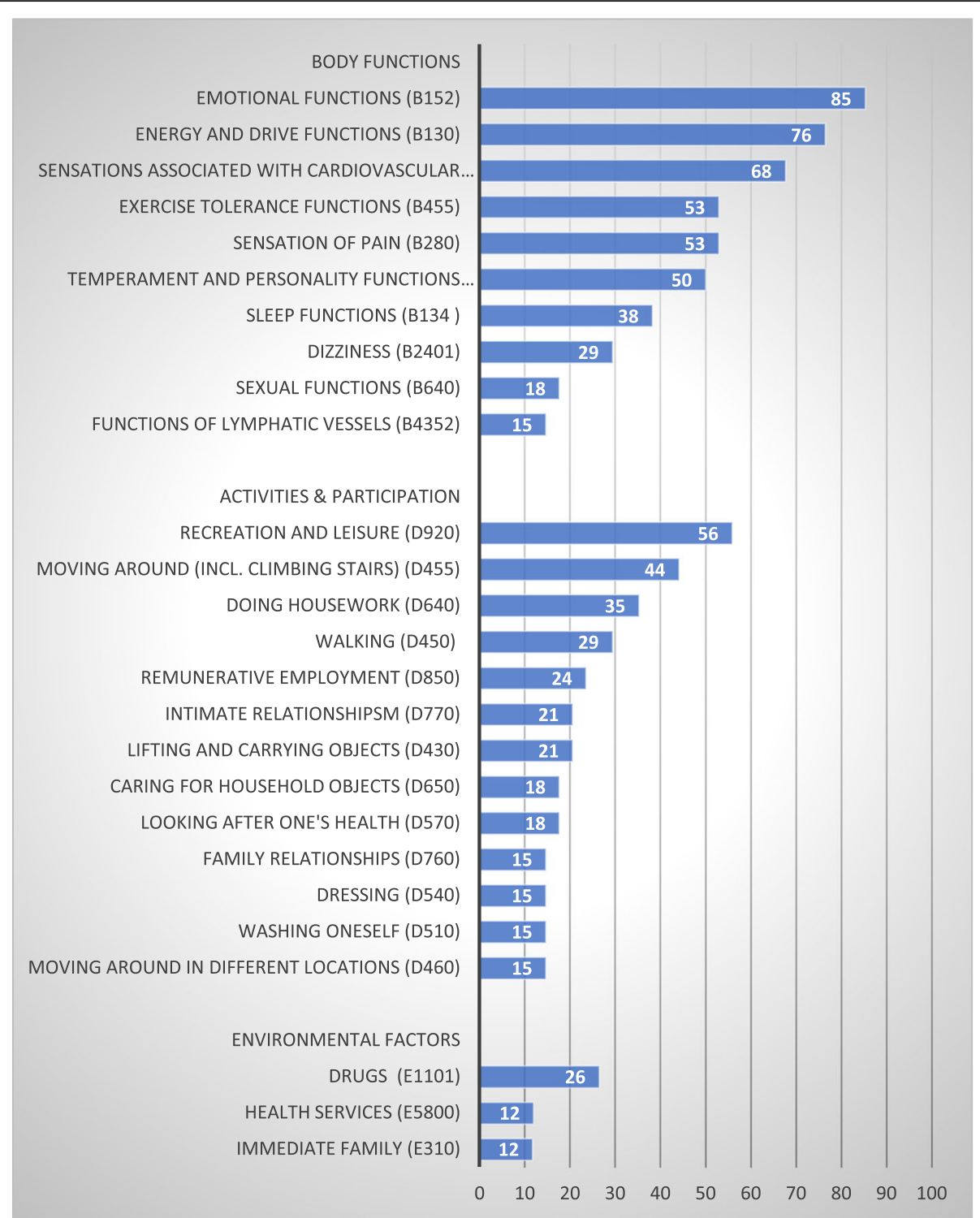

Fig. 2 Most frequently mapped ICF categories (in percent) across the 34 PROMs with the results stratified by Body functions, Activities \& Participation, and Environmental factors

mobility, household tasks, major life areas, interactions, and recreation. For heart failure, the MSAS-HF covers the widest range of different aspects but with a main focus on problems within mental, sensory, and cardiovascular functions and only one item about Activities \& Participation ("Focusing attention"). If the focus should be on activities of daily living, recreation and leisure activities, medication, and support, then the Left Ventricular Dysfunction Questionnaire (LVD-36) might be more appropriate. For ischemic heart disease, the Summary Index for the Assessment of Quality of Life in Angina Pectoris covers most different aspects. The core of this instrument is a broad spectrum of mental functions, e.g. mood, energy level, motivation, emotions, sleep, attention, and thoughts, but it also addresses Activities \& Participation, e.g. walking and climbing stairs, doing housework, and aspects related to work, recreation, and leisure.

The present study is the first content comparison of heart disease-specific PROMs. It showed that different PROMs focus on different aspects of QoL and that questions on Body functions were the most frequently asked and were included in all 34 PROMs. Obviously, biomedical issues like heart functions, the sensations with cardiovascular functions, emotions, and energy level were dominant in the PROMs. However, our results have identified other issues that were only addressed in a few PROMs, for example, recreation and leisure activities, climbing stairs, intimate and family relationships, 
medication tolerance, and support from family. Those issues are as well included in the ICF Core Set (ICF-CS) for ischemic heart disease [64]. The latter can be seen as an international standard of ICF categories important for patients with heart diseases that is based on a consensus and decision-making process involving international experts from diverse disciplines representing the six WHO world regions. Prior to the consensus process, the experts were provided with evidence from the clinical (multicenter study), health professionals' (expert survey), researchers' (literature review) perspective and the perspective of patients with the cardiological conditions (qualitative study) [65]. With this convenient evidence, it is argued that the identified issues are worth addressing in clinical counseling and should be included in PROMs in order to capture patients' experiences of their health status from a bio-psycho-social perspective.

There are some limitations of the present study that should be mentioned. First, only PROMs measuring health, health-related states, QoL, and symptoms and available in English and validated for use in adults were included. This means that our results are valid for the adult patient with heart disease and not focusing on any single symptom such as fatigue or locus of control. Second, the literature search was carried out in PubMed only and the search was limited to the title. PubMed is the largest database for medical research and therefore judged as most relevant. The strategy to limit the search to the title was conducted to delimit the results since some of the search terms are very broad and resulted initially in a very large number of articles of no relevance without this restriction. The search strategy and terms were also discussed with a librarian with special competence in medical science and literature searches. Additionally, the CESAR expert group, consisting of more than 20 researchers within cardiovascular disease, confirmed the result and cud only present additionally four PROMs not identified in the literature search. Third, the linking of the PROMs was performed by two researchers very familiar with the ICF and the application of the ICF linking rules. Other researchers might have come up with slightly different linking results, but this is not likely to have significantly altered the conclusions drawn here.

\section{Conclusions}

This scoping review and mapping exercises give an overview of several PROMs available for patients with different types of heart diseases and provide a detailed comparison of their content. These findings can help clinicians and researchers to identify PROMs of high relevance depending on which aspects they want to focus on. A great majority of the PROMs have been developed for a specific heart disease (mainly for heart failure), and none exist for valve diseases or congenital heart diseases. However, many patients suffer from more than one heart disease at the same time, and this stresses the importance of generic PROMs to be used for all different types of heart diseases. This study identified 10 Body functions, 13 aspects of Activities \& Participation, and 2 aspects of Environmental factors that should be included in a generic PROM for patients with different types of heart diseases in order to capture patients' experiences of their health status from a bio-psycho-social perspective. The results of the present study might be a good starting point for further development of PROMs for patients with heart diseases.

\section{What's new}

- There are 5 PROMs for heart diseases in general, 6 disease-specific PROMs for cardiac arrhythmia, 14 PROMs for heart failure, and 9 PROMs for ischemic heart disease.

- There is a lack of disease-specific PROMs for valve disease and congenital heart disease.

- From a bio-psycho-social perspective, all PROMs included aspects of Body functions, but Activities \& Participation and Environmental factors were less often included (missing in 6 and 18 PROMs, respectively).

- The most common specific aspects were about individuals' emotions and mood, individuals' energy level and motivation, and individuals' sensations with cardiovascular functions.

- Less common specific aspects were about medication tolerance, support of family, doing housework, employment, sleep, and sexual relationship, and these were only included in few PROMs.

- There is a need for further development of heart disease-specific PROMs that can support person-centered care.

\section{Supplementary information}

Supplementary information accompanies this paper at https://doi.org/10. 1186/s41687-019-0165-7.

Additional file 1. Overview of the Pubmed search strings that were used to identify specific PROMs for heart diseases in general, cardiac arrhythmia, heart failure, ischemic heart disease, valve disease and congenital heart disease. The literature search was conducted in January 2018.

Additional file 2. Overview of different aspects measured by each PROMs $(n=34)$ linked to ICF catgories from the component 'Body Functions' stratified by heart diseases.

Additional file 3. Overview of different aspects measured by each PROMs $(n=34)$ linked to ICF catgories from the component 'Activities and Participation' stratified by heart diseases.

Additional file 4. Overview of different aspects measured by each PROMs $(n=34)$ linked to ICF catgories from the component 'Environmental factors' stratified by heart diseases.

\section{Abbreviations}

ICF: International Classification of Functioning, Disability and Health; PROM: Patient-reported outcome measure; QoL: Quality of life; WHO: World Health Organization

Authors' contributions

All authors contributed to the design of the study. BA and KÅ conducted the literature search in collaboration with a librarian. BA and $M C$ did the contentanalysis. BA and KÅ drafted the paper. MC, DM, BF, and JM reviewed the 
paper and BA completed it in collaboration with all authors who approved the final version prior to submission.

\section{Funding}

Open access funding provided by University of Gothenburg.

\section{Availability of data and materials}

This article is entirely based on data and materials that have been published, are publicly available (thus, accessible to any interested researcher), and appear in the references list.

\section{Ethics approval and consent to participate}

Not applicable.

\section{Consent for publication}

Not applicable.

\section{Competing interests}

The authors declare that they have no competing interests.

\section{Author details}

${ }^{1}$ Department of Food and Nutrition, and Sport Science, Faculty of Education, University of Gothenburg, PO Box 300, 40530 Gothenburg, Sweden. ${ }^{2}$ The Jönköping Academy for Improvement of Health and Welfare, School of Health Sciences, Jönköping University, Jönköping, Sweden. ${ }^{3}$ Institute for Medical Information Processing, Biometry and Epidemiology (IBE), Chair of Public Health and Health Services Research, Research Unit for Biopsychosocial Health, LMU Munich, Munich, Germany. ${ }^{4}$ Pettenkofer School of Public Health, Munich, Germany. ${ }^{5}$ ICF Research Branch, a cooperation partner within the WHO Collaborating Centre for the Family of International Classifications in Germany (at DIMDI)*, Nottwil, Switzerland. ${ }^{6}$ Department of Nursing, School of Health and Welfare, Jönköping University, Jönköping, Sweden. ${ }^{7}$ Centre of Interprofessional Collaboration within Emergency care (CICE), Linnaeus University, Växjö, Sweden. ${ }^{8}$ Faculty of Health and Life Sciences, Linnaeus University, Kalmar/Näxjö, Sweden. ${ }^{9}$ The Research Section, Region Kalmar County, Kalmar, Sweden.

Received: 27 August 2019 Accepted: 11 December 2019 Published online: 23 January 2020

\section{References}

1. McAloon, C. J., Boylan, L. M., Hamborg, T., Stallard, N., Osman, F., Lim, P. B., et al. (2016). The changing face of cardiovascular disease 2000-2012: An analysis of the world health organisation global health estimates data. International Journal of Cardiology, 224, 256-264.

2. Moon, C., Phelan, C. H., Lauver, D. R., \& Bratzke, L. C. (2015). Is sleep quality related to cognition in individuals with heart failure? Heart Lung, 44(3), 212-218.

3. Juenger, J., Schellberg, D., Kraemer, S., Haunstetter, A., Zugck, C., Herzog, W., et al. (2002). Health related quality of life in patients with congestive heart failure: Comparison with other chronic diseases and relation to functional variables. Heart, 87(3), 235-241.

4. Mendes de Leon, C. F., Grady, K. L., Eaton, C., Rucker-Whitaker, C., Janssen, I., Calvin, J., et al. (2009). Quality of life in a diverse population of heart failure patients: Baseline findings from the Heart Failure Adherence and Retention Trial (HART). Journal of Cardiopulmonary Rehabilitation and Prevention, 29(3), $171-178$.

5. Racca, V., Spezzaferri, R., Modica, M., Mazzini, P., Jonsdottir, J., De Maria, R., et al. (2010). Functioning and disability in ischaemic heart disease. Disability and Rehabilitation, 32(S1), S42-SS9.

6. Kovacs, A. H., Sears, S. F., \& Saidi, A. S. (2005). Biopsychosocial experiences of adults with congenital heart disease: Review of the literature. American Heart Journal, 150(2), 193-201.

7. Anker, S. D., Agewall, S., Borggrefe, M., Calvert, M., Jaime Caro, J., Cowie, M. R., et al. (2014). The importance of patient-reported outcomes: A call for their comprehensive integration in cardiovascular clinical trials. European Heart Journal, 35(30), 2001-2009.

8. International Alliance of Patients' Organizations. (2007). What is PatientCentred Healthcare? A Review of Definitions and Principles. London: IAPO.

9. Nelson, E. C., Eftimovska, E., Lind, C., Hager, A., Wasson, J. H., \& Lindblad, S. (2015). Patient reported outcome measures in practice. BMJ, 350, g7818.
10. Ekman, I., Swedberg, K., Taft, C., Lindseth, A., Norberg, A., Brink, E., et al. (2011). Person-centered care - Ready for prime time. European Journal of Cardiovascular Nursing, 10(4), 248-251.

11. Wilberforce, M., Challis, D., Davies, L., Kelly, M. P., Roberts, C., \& Loynes, N. (2016). Person-centredness in the care of older adults: A systematic review of questionnaire-based scales and their measurement properties. BMC Geriatrics, 16(1), 63

12. U.S. Department of Health and Human Services FDA Center for Drug Evaluation and Research. (2006). Guidance for industry: patient-reported outcome measures: use in medical product development to support labeling claims: Draft guidance. Health and Quality of Life Outcomes, 4, 79.

13. Meadows, K. A. (2011). Patient-reported outcome measures: An overview. British Journal of Community Nursing, 16(3), 146-151.

14. Baumhauer, J. F., \& Bozic, K. J. (2016). Value-based healthcare: Patientreported outcomes in clinical decision making. Clinical Orthopaedics and Related Research, 474(6), 1375-1378.

15. Bradley, S. M., Strauss, C. E., \& Ho, P. M. (2017). Value in cardiovascular care Heart, 103(16), 1238-1243.

16. Norekval, T. M., Falun, N., Fridlund, B., \& Patient-Reported Outcomes C. (2016). Patient-reported outcomes on the agenda in cardiovascular clinical practice. European Journal of Cardiovascular Nursing, 15(2), 108-111.

17. Thompson, D. R., Ski, C. F., Garside, J., \& Astin, F. (2016). A review of healthrelated quality of life patient-reported outcome measures in cardiovascular nursing. European Journal of Cardiovascular Nursing, 15(2), 114-125.

18. Bell, S. P., \& Saraf, A. A. (2016). Epidemiology of multimorbidity in older adults with cardiovascular disease. Clinics in Geriatric Medicine, 32(2), 215-21+.

19. Forman, D. E., Maurer, M. S., Boyd, C., Brindis, R., Salive, M. E., Home, F. M., et al. (2018). Multimorbidity in older adults with cardiovascular disease. Journal of the American College of Cardiology, 71(19), 2149-2161.

20. Fayed, N., Cieza, A., \& Bickenbach, J. E. (2011). Linking health and healthrelated information to the ICF: A systematic review of the literature from 2001 to 2008. Disability and Rehabilitation, 33(21-22), 1941-1951.

21. Cieza, A., Bickenbach, J., \& Chatterji, S. (2008). The ICF as a conceptual platform to specify and discuss health and health-related concepts. Gesundheitswesen, 70(10), 569-571.

22. Evans, D. Overview of methods. In C. W. B. Roe (Ed.), Reviewing research evidence for nursing practice (pp. 137-148). Oxford: Blackwell Publishing.

23. Cieza, A., Brockow, T., Ewert, T., Amman, E., Kollerits, B., Chatterji, S., et al. (2002). Linking health-status measurements to the international classification of functioning, disability and health. Journal of Rehabilitation Medicine, 34(5), 205-210.

24. Cieza A, Fayed N, Bickenbach J, Prodinger B. (2019). Refinements of the ICF Linking Rules to strengthen their potential for establishing comparability of health information. Disability and Rehabilitation, 41(5):574-83.

25. Cieza, A., Geyh, S., Chatterji, S., Kostanjsek, N., Ustun, B., \& Stucki, G. (2005). ICF linking rules: An update based on lessons learned. Journal of Rehabilitation Medicine, 37(4), 212-218.

26. Hlatky, M. A., Boineau, R. E., Higginbotham, M. B., Lee, K. L., Mark, D. B., Califf, R. M., et al. (1989). A brief self-administered questionnaire to determine functional capacity (the Duke activity status index). The American Journal of Cardiology, 64(10), 651-654.

27. Alonso, J., Permanyer-Miralda, G., Cascant, P., Brotons, C., Prieto, L., \& SolerSoler, J. (1997). Measuring functional status of chronic coronary patients. Reliability, validity and responsiveness to clinical change of the reduced version of the Duke Activity Status Index (DASI). European Heart Journal, 18(3), 414-419.

28. Oldridge, N., Hofer, S., McGee, H., Conroy, R., Doyle, F., \& Saner, H. (2014). The HeartQoL: Part II. Validation of a new core health-related quality of life questionnaire for patients with ischemic heart disease. European Journal of Preventive Cardiology, 21(1), 98-106.

29. Avis, N. E., Smith, K. W., Hambleton, R. K., Feldman, H. A., Selwyn, A., \& Jacobs, A. (1996). Development of the multidimensional index of life quality. A quality of life measure for cardiovascular disease. Medical Care, 34(11), $1102-1120$.

30. Ferrans, C., \& Powers, M. (1985). Quality of life index: Development and psychometric properties. Advances in Nursing Science, 8, 15-24.

31. Wan, C. H., Li, H. Z., Fan, X. J., Yang, R. X., Pan, J. H., Chen, W. R., et al. (2014). Development and validation of the coronary heart disease scale under the system of quality of life instruments for chronic diseases QLICD-CHD: Combinations of classical test theory and generalizability theory. Health and Quality of Life Outcomes, 12(1), 82. 
32. Badia, X., Arribas, F., Ormaetxe, J. M., Peinado, R., \& de Los Terreros, M. S. (2007). Development of a questionnaire to measure health-related quality of life (HRQoL) in patients with atrial fibrillation (AF-QoL). Health and Quality of Life Outcomes, 5, 37.

33. Walfridsson, U., Arestedt, K., \& Stromberg, A. (2012). Development and validation of a new arrhythmia-specific questionnaire in tachycardia and arrhythmia (ASTA) with focus on symptom burden. Health and Quality of Life Outcomes, 10, 44.

34. Walfridsson, U., Stromberg, A., \& Arestedt, K. (2015). Development and validation of an arrhythmia-specific scale in tachycardia and arrhythmia with focus on health-related quality of life. Journal of Cardiovascular Nursing, $30(2), 98-108$

35. Härdén, M., Nystrom, B., Kulich, K., Carlsson, J., Bengtson, A., \& Edvardsson, N. (2009). Validity and reliability of a new, short symptom rating scale in patients with persistent atrial fibrillation. Health and Quality of Life Outcomes, 7, 65.

36. Spertus, J. A., Winder, J. A., Dewhurst, T. A., Deyo, R. A., Prodzinski, J., McDonell, M., et al. (1995). Development and evaluation of the Seattle Angina Questionnaire: A new functional status measure for coronary artery disease. Journal of the American College of Cardiology, 25(2), 333-341.

37. Wood, K. A., Stewart, A. L., Drew, B. J., Scheinman, M. M., \& Frolicher, E. S. (2009). Development and initial psychometric evaluation of the patient perspective of arrhythmia questionnaire. Research in Nursing \& Health, 32(5), 504-516.

38. Braganca, E. O., Filho, B. L., Maria, V. H., Levy, D., \& de Paola, A. A. (2010). Validating a new quality of life questionnaire for atrial fibrillation patients. International Journal of Cardiology, 143(3), 391-398.

39. Mannheimer, B., Andersson, B., Carlsson, L., \& Wahrborg, P. (2007). The validation of a new quality of life questionnaire for patients with congestive heart failure-an extension of the cardiac health profile. Scandinavian Cardiovascular Journal, 41(4), 235-241.

40. van Kessel, P., de Boer, D., Hendriks, M., \& Plass, A. M. (2017). Measuring patient outcomes in chronic heart failure: Psychometric properties of the care-related quality of life survey for chronic heart failure (CaReQoL CHF). BMC Health Services Research, 17(1), 536.

41. Guyatt, G. H., Nogradi, S., Halcrow, S., Singer, J., Sullivan, M. J., \& Fallen, E. L. (1989). Development and testing of a new measure of health status for clinical trials in heart failure. Journal of General Internal Medicine, 4(2), 101-107.

42. Kamphus, M., Zwinderman, K. H., Vogels, T., Vliegen, H. W., Kamphuis, R. P., Ottenkamp, J., et al. (2004). A cardiac-specific health-related quality of life module for young adults with congenital heart disease: Development and validation. Quality of Life Research, 13(4), 735-745.

43. Kolip, P., \& Schmidt, B. (1999). Der Fragebogen zur Erfassung körperlichen Wohlbefindens (FEW-16). Konstruktion und erste Validierung. Zeitschrift für Gesundheitspsychologie, 7, 77-87.

44. Padillia, K. M., Gallani, M., \& Colombo, R. C. R. (2007). Validity of an instrument to measure the impact of valve heart disease on the patient's daily life. Journal of Clinical Nursing, 16(7), 1285-1291.

45. Jurgens, C. Y., Fain, J. A., \& Riegel, B. (2006). Psychometric testing of the heart failure somatic awareness scale. Journal of Cardiovascular Nursing, 21(2), 95-102.

46. Green, C. P., Porter, C. B., Bresnahan, D. R., \& Spertus, J. A. (2000) Development and evaluation of the Kansas City cardiomyopathy questionnaire: A new health status measure for heart failure. Journal of the American College of Cardiology, 35(5), 1245-1255.

47. O'Leary, C. J., \& Jones, P. W. (2000). The left ventricular dysfunction questionnaire (LVD-36): Reliability, validity, and responsiveness. Heart, 83(6), 634-640.

48. Zambroski, C. H., Moser, D. K., Bhat, G., \& Ziegler, C. (2005). Impact of symptom prevalence and symptom burden on quality of life in patients with heart failure. European Journal of Cardiovascular Nursing, 4(3), 198-206.

49. Rector, T. S., \& Cohn, J. N. (1992). Assessment of patient outcome with the Minnesota living with heart failure questionnaire: Reliability and validity during a randomized, double-blind, placebo-controlled trial of pimobendan. American Heart Journal, 124(4), 1017-1025

50. Wiklund, I., Lindvall, K., Swedberg, K., \& Zupkis, R. V. (1987). Self-assessment of quality of life in severe heart failure. An instrument for clinical use. Scandinavian Journal of Psychology, 28(3), 220-225.

51. Heo, S., Moser, D. K., Pressler, S. J., Dunbar, S. B., Mudd-Martin, G., \& Lennie, T. A. (2014). Psychometric properties of the symptom status questionnaireheart failure. Canadian Journal of Cardiovascular Nursing, 30(2), 136-144.

52. Fu, T. C., Lin, Y. C., Chang, C. M., Chou, W. L., Yuan, P. H., Liu, M. H., et al. (2016). Validation of a new simple scale to measure symptoms in heart failure from traditional Chinese medicine view: A cross-sectional questionnaire study. Bmc Complementary and Alternative Medicine, 16(1), 342.

53. Lerner, D. J., Amick, B. C., Malspeis, S., Rogers, W. H., Gomes, D. R. J., \& Salem, D. N. (1998). The angina-related limitations at work questionnaire. Quality of Life Research, 7(1), 23-32.

54. Marquis, P., Fayol, C., \& Joire, J. E. (1995). Clinical validation of a quality of life questionnaire in angina pectoris patients. European Heart Journal, 16(11), 1554-1560.

55. Lewin, R. J., Thompson, D. R., Martin, C. R., Stuckey, N., Devlen, J., Michaelson, S., et al. (2002). Validation of the cardiovascular limitations and symptoms profile (CLASP) in chronic stable angina. Journal of Cardiopulmonary Rehabilitation and Prevention, 22(3), 184-191.

56. Thompson, D. R., Jenkinson, C., Roebuck, A., Lewin, R. J. P., Boyle, R. M., \& Chandola, T. (2002). Development and validation of a short measure of health status for individuals with acute myocardial infarction: The myocardial infarction dimensional assessment scale (MIDAS). Quality of Life Research, 11(6), 535-543.

57. Rukholm, E., \& McGirr, M. (1994). A quality-of-life index for clients with ischemic heart disease: Establishing reliability and validity. Rehabilitation Nursing, 19(1), 12-16.

58. Valenti, L., Lim, L., Heller, R. F., \& Knapp, J. (1996). An improved questionnaire for assessing quality of life after acute myocardial infarction. Quality of Life Research, 5(1), 151-161.

59. Wilson, A., Wiklund, I., Lahti, T., \& Wahl, M. (1991). A summary index for the assessment of quality of life in angina pectoris. Journal of Clinical Epidemiology, 44(9), 981-988.

60. Rose, G. A. (1962). The diagnosis of ischaemic heart pain and intermittent claudication in field surveys. Bulletin of the World Health Organization, 27, 645-658.

61. Lawlor, D. A., Adamson, J., \& Ebrahim, S. (2003). Performance of the WHO Rose angina questionnaire in post-menopausal women: Are all of the questions necessary? Journal of Epidemiology and Community Health, 57(7), 538-541.

62. Van der Wees, P. J., Nijhuis-Van der Sanden, M. W. G., Ayanian, J. Z., Black, N., Westert, G. P., \& Schneider, E. C. (2014). Integrating the use of patient-reported outcomes for both clinical practice and performance measurement: Views of experts from 3 countries. Milbank Quarterly, 92(4), 754-775.

63. Campkin, L. M., Boyd, J. M., \& Campbell, D. J. T. (2017). Coronary artery disease patient perspectives on exercise participation. Journal of Cardiopulmonary Rehabilitation and Prevention, 37(5), 305-314.

64. Cieza, A., Stucki, A., Geyh, S., Berteanu, M., Quittan, M., Simon, A., et al. (2004). ICF core sets for chronic ischaemic heart disease. Journal of Rehabilitation Medicine, 36, 94-99.

65. Selb, M., Escorpizo, R., Kostanjsek, N., Stucki, G., Ustun, A., \& Cieza, A. (2015). A guide on how to develop an international classification of functioning, disability and health core set. European Journal of Physical and Rehabilitation Medicine, 51(1), 105-117.

\section{Publisher's Note}

Springer Nature remains neutral with regard to jurisdictional claims in published maps and institutional affiliations.

\section{Submit your manuscript to a SpringerOpen ${ }^{\circ}$ journal and benefit from:}

- Convenient online submission

- Rigorous peer review

- Open access: articles freely available online

- High visibility within the field

- Retaining the copyright to your article

Submit your next manuscript at $>$ springeropen.com 